\title{
Naso-Labio-Palatine Clefts: Humanitarian Care in Togo
}

\section{Saliou Adam 1,2*, Hamza Dolès Sama3 ${ }^{3}$, Winga Foma2 ${ }^{2}$, Haréfétéguéna Bissa ${ }^{1,2}$, Palakina Agoda4, Bina Béténora1, Essobozou Plaoudézina Pegbessou ${ }^{5}$, Bathokédéou Amana², Essohanam Boko5, Mohaman Awalou Djibril', Eyawèlohn Kpemissi²}

\author{
${ }^{1}$ Department of Stomatology and Maxillofacial Surgery at Sylvanus Olympio University Teaching Hospital of Lomé, Lomé, Togo \\ ${ }^{2}$ Department of ENT at Sylvanus Olympio University Teaching Hospital of Lomé, Lomé, Togo \\ ${ }^{3}$ Department of Anesthesia and Intensive Care at Sylvanus Olympio University, Lomé, Togo \\ ${ }^{4}$ Department of Stomatology at Campus University Teaching Hospital of Lomé Teaching Hospital of Lomé, Lomé, Togo \\ ${ }^{5}$ Department of ENT at Campus University Teaching Hospital of Lomé, Lomé, Togo \\ ${ }^{6}$ Military Medical Department at Sylvanus Olympio University Teaching Hospital of Lomé, Lomé, Togo \\ Email: *saliou.adam1@yahoo.com
}

How to cite this paper: Adam, S., Sama, H.D., Foma, W., Bissa, H., Agoda, P., Béténora, B., Pegbessou, E.P., Amana, B., Boko, E., Djibril, M.A. and Kpemissi, E. (2021) Naso-Labio-Palatine Clefts: Humanitarian Care in Togo. Open Journal of Stomatology, 11, 411-421. https://doi.org/10.4236/ojst.2021.1110036

Received: August 29, 2021

Accepted: October 5, 2021

Published: October 8, 2021

Copyright ( 2021 by author(s) and Scientific Research Publishing Inc. This work is licensed under the Creative Commons Attribution International License (CC BY 4.0).

http://creativecommons.org/licenses/by/4.0/ (c) (i) Open Access

\begin{abstract}
Introduction: The management of nasolabial-palatal clefts in precarious environments is one of the topics most addressed by many humanitarian missions, especially in Africa and Asia. The aim of our study was to propose a humanitarian and not expensive care to the patients presenting with facial clefts during the fairgrounds in disadvantaged areas. Patients and Method: We carried out a prospective study on 32 patients who were operated with very limited means during the mobile clinics inside Togo during the year 2013. These patients were followed over a period of one year after their surgery. Included in our series were native patients with facial clefts, who had no means of managing their condition, and who therefore needed humanitarian support. We have reported the clinical history of some patients to illustrate our results. Results: Our study included 32 children, including 15 boys and 17 girls, with a sex ratio of around 1 . The average age of patients was 5 years, with extremes of 6 months and 13 years. We performed 13 clefts (including 12 unilateral clefts and 1 bilateral cleft), 17 clefts palate (including 12 unilateral clefts and 5 bilateral clefts), and 2 velar clefts. We described the clinical history of a few patients in this humanitarian setting and showed the surgical results obtained.
\end{abstract}

\section{Keywords}

Nasolabial-Palatal Clefts, Humanitarian Care, Togo 


\section{Introduction}

Certain malformative and tumoral pathologies are not treated in underdeveloped countries because of the lack of an adequate technical platform, qualified personnel or knowledge. This is particularly true for nasolabial-palatal clefts. Thus, the management of nasolabial-palatal clefts in precarious environments is one of the topics most addressed by many humanitarian missions, especially in Africa and Asia [1] [2] [3]. In some western countries, nasolabial-palatal slits account for about 1.5 per 1000 births [2]. In Togo, they represent 1/500 to 1/700 births. The aim of our study was to propose a humanitarian and not expensive care to the patients presenting with facial clefts during the fairgrounds in disadvantaged areas. The objectives of the surgical treatment in this context were to solve two problems essentially: the functional problem on the veil to allow a correct phonation but especially a satisfactory swallowing; and on the palate to ensure a tightness of the oral cavity and nasal cavity allowing a proper diet; and the aesthetic problem by restoring the labial muscle strap and correcting the deformations of the nostrils. This allowed the socialization of the child with a normal education, because a cleft lip leads in some areas to social marginalization.

\section{Patients and Method}

We carried out a prospective study on 32 patients who were operated with very limited means during the mobile clinics inside Togo during the year 2013. These patients were followed over a period of one year after their surgery. Included in our Study were native patients with facial clefts, who had no means of managing their condition, and who therefore needed humanitarian support. Their parents may agree also with the treatment. Patients with other associated pathologies were excluded from the study, and patients which had the possibility of managing their pathology in specialized settings. The operative techniques practiced in our series were essentially the Millard technique for the repair of nasolabial clefts, and the Wardill-Bardach technique [4] [5] [6] for the repair of palato-velar clefts. We have reported the clinical history of some patients to illustrate our results.

\section{Results}

The study included 32 children, including 15 boys and 17 girls, with 1 sex ratio around 1 (Table 1). The average age of patients was 5 years, with extremes of 6 months and 13 years. Figure 1 summarizes the distribution of patients by age group.

We performed 13 clefts (including 12 unilateral clefts and 1 bilateral cleft), 17 cleft palate (including 12 unilateral clefts and 5 bilateral clefts), and 2 velar clefts. The following is a description of the clinical history of a few patients in this humanitarian setting and the surgical results obtained.

1) XX1, 9 years old, she was a young girl with an incomplete unilateral labial-alveolar-palatal cleft. She was operated using the Millard technique. Manage- 
ment of the alveolar cleft was ensured by simple confrontation of the 2 banks and the establishment of a dental arch. Healing was guided by the labial closure. Two surgical procedures were necessary. The first stage involved labial surgery and nasal wings for an essentially aesthetic result, and the second was related to palatal surgery and management of the alveolar cleft for functional outcome (Figure 2).

2) XY1, Double reason. Human reason: to give joy to the caregiver and his entourage; but also the pleasure for the caregiver to have been chosen by the leaders of the non-governmental organization (ONG) and to be able to practice a surgery different from that of the metropolis and also to have an adventure and to see exoticism... Technical reason: care and teaching, knowing that these reasons are different for the novice professional and the experienced professional 6

Table 1. Distribution of patients by sex.

\begin{tabular}{cccc}
\hline & Female & Male & Total \\
\hline Effective & 17 & 15 & 32 \\
Percentage & $53 \%$ & $47 \%$ & $100 \%$ \\
\hline
\end{tabular}

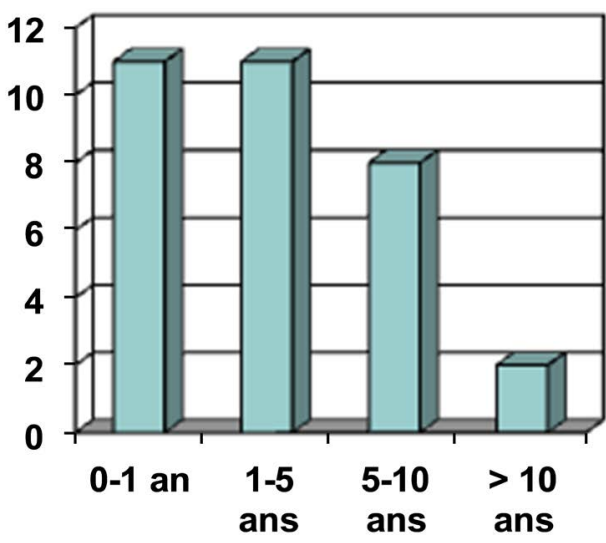

\section{$\square$ nombre}

Figure 1. Distribution of patients by age group.

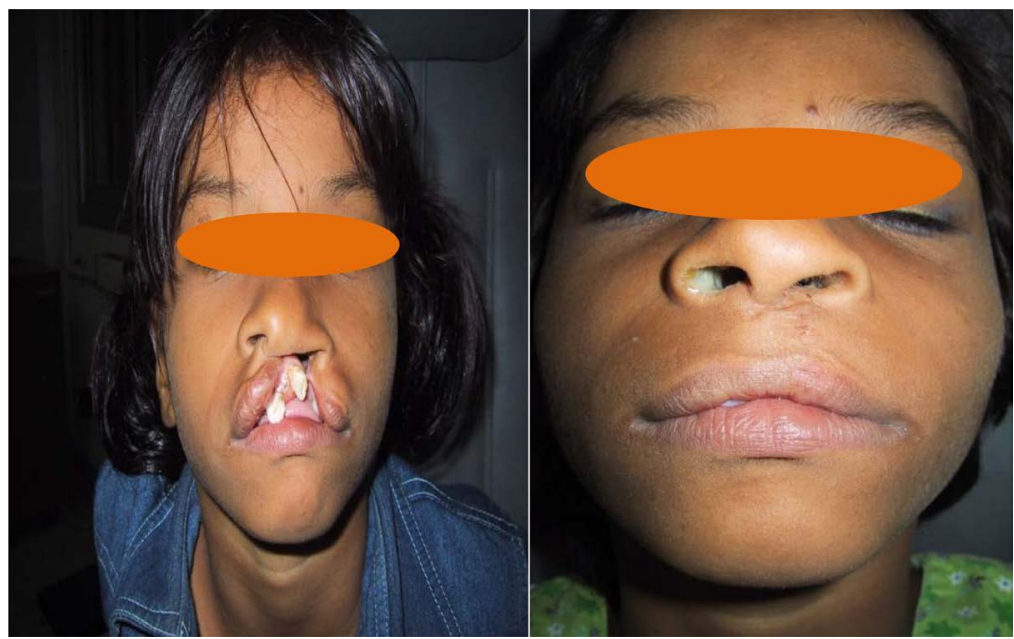

Figure 2. Before and after surgery. 
years old. He was a young boy who had a bilateral cleft lip without pro labium, in which it was necessary to perform a labial surgery to rebuild the philtrum. The treatment was performed in a single operation time, by bilateral lab surgery using the Millard technique, thus recreating the philthral ridges, and avoiding retraction of the lip (Figure 3).

3) XY2, 6 months, he was an infant with a complete unilateral left labio-alveolo-palatal cleft. This infant had nutritional problems related to sucking difficulties, both for breast-feeding and bottle-feeding. The surgery was performed in 2 stages with a rhinoplasty time. The first time involved Millard's labio-rhinoplasty with a perfect labial result, but a philtrum slightly shifted to the left side of the cleft. The second time concerned the palato bike plasty associated with gingivoperiostoplasty (Figure 4).

4) $\mathrm{XY} 3,2$ years, he was an infant who had a bilateral full labio-alveolo-palatal cleft with an important pro labium. The approach to his care was to recreate a philtrum and reinsert the pro labium between the lateral banks of the gingiva. We had opted to postpone taking care of the pro labium, but the child was lost sight of after the first surgery. The first surgical time involved lab repair with the

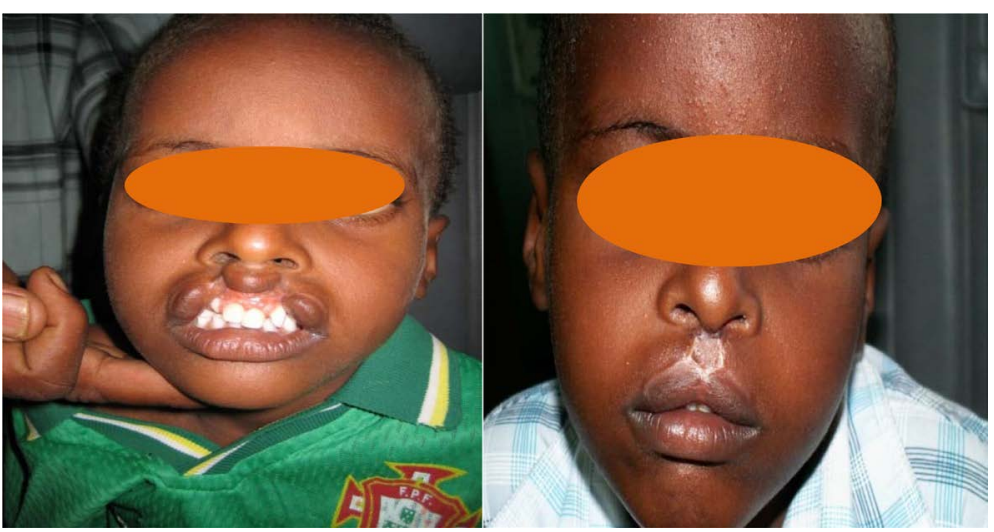

Figure 3. Before and after surgery.

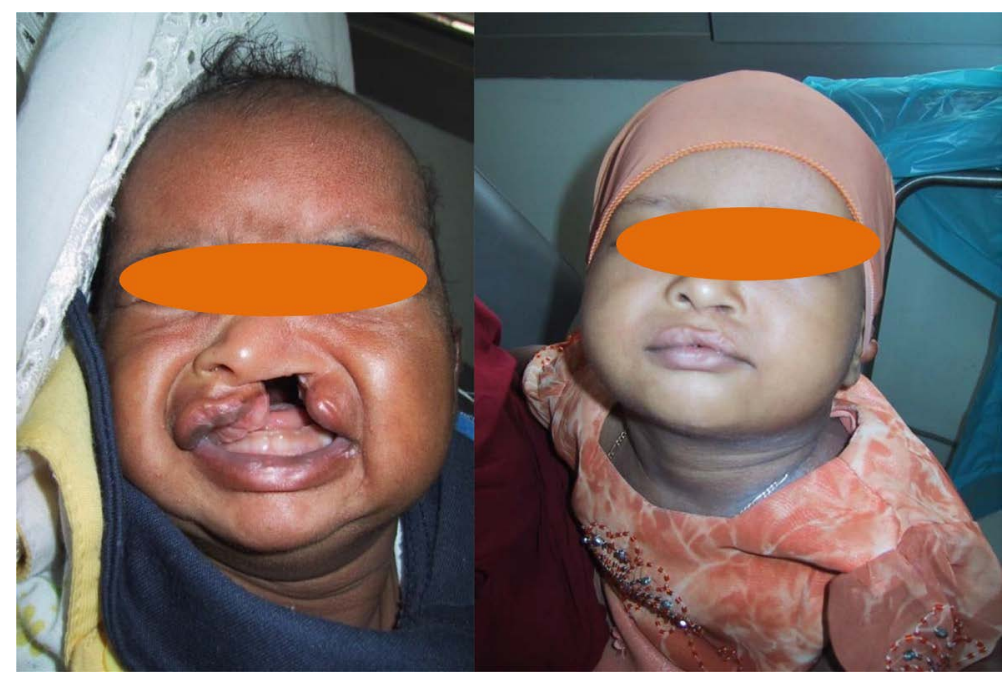

Figure 4. Before and after surgery. 
Bilateral Millard Technique. The second time was the Wardill-Bardach palatine bike (Figure 5).

5) XX2, 13 years old, she was a young girl with a complete unilateral cleft lip and alveolar cleft palate associated with a cyst of the root of the nose, suggesting a case of medial facial cleft with the presence of a blatant hypertelorism. The repair was performed in two stages. The first stage involved labile rhinoplasty using the Millard technique associated with gingivoperiostoplasty, and the second was palatal cycling using the Wardill-Bardach technique (Figure 6).

6) $\underline{\mathrm{XX} 3}, 11$ years old, he was a child already operated on a bilateral labio-alveolo-palatal cleft a few years ago. The care was stopped for lack of financial means. In this child there was a great deal of concern for the pro labium, and it was impossible to remove it, lest the teeth and the alveolar bone should be removed, and a defect in the hard palate would appear with oral communication. The therapeutic approach was to perform a complementary gesture on the lip
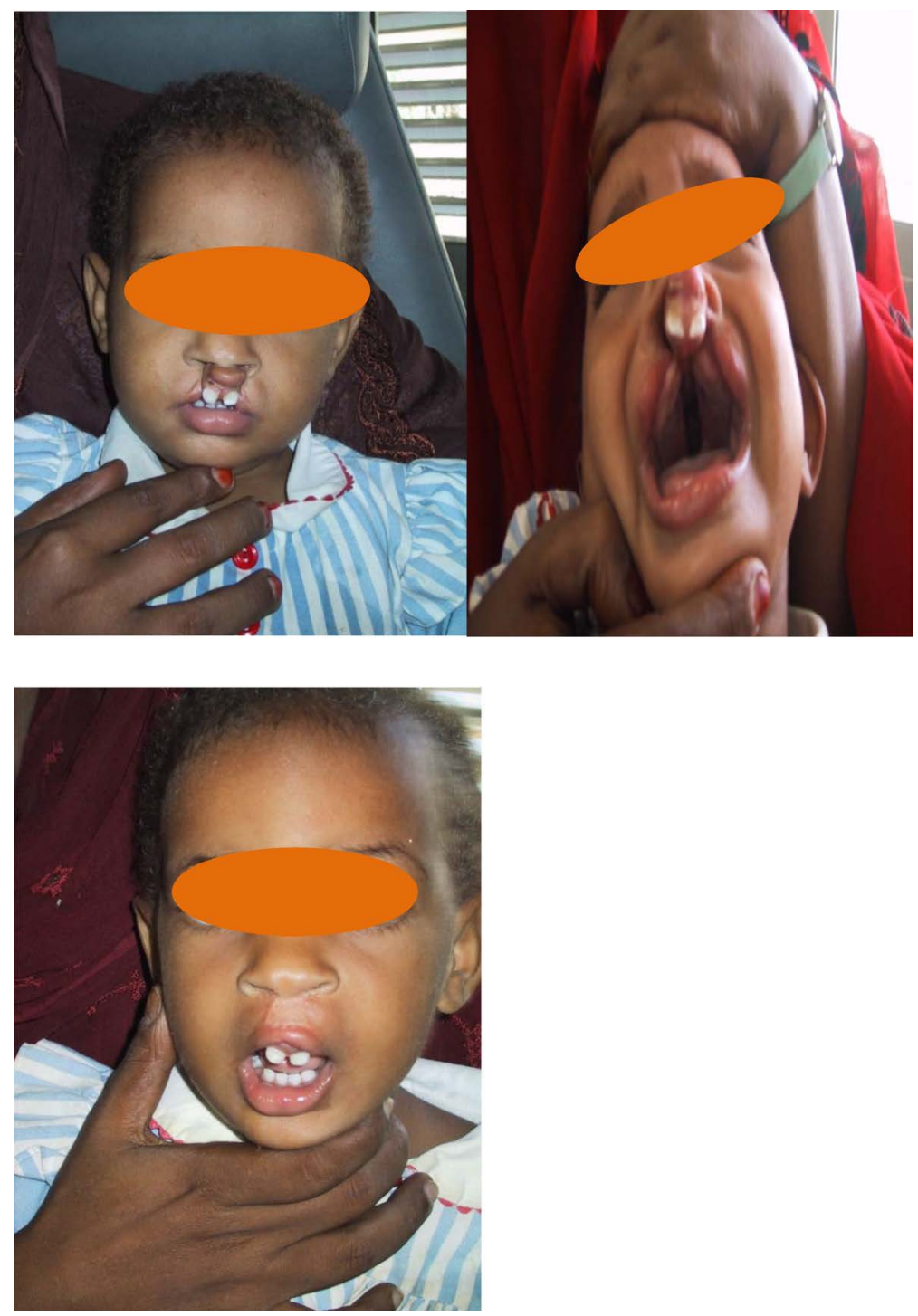

Figure 5. Before and after surgery. 

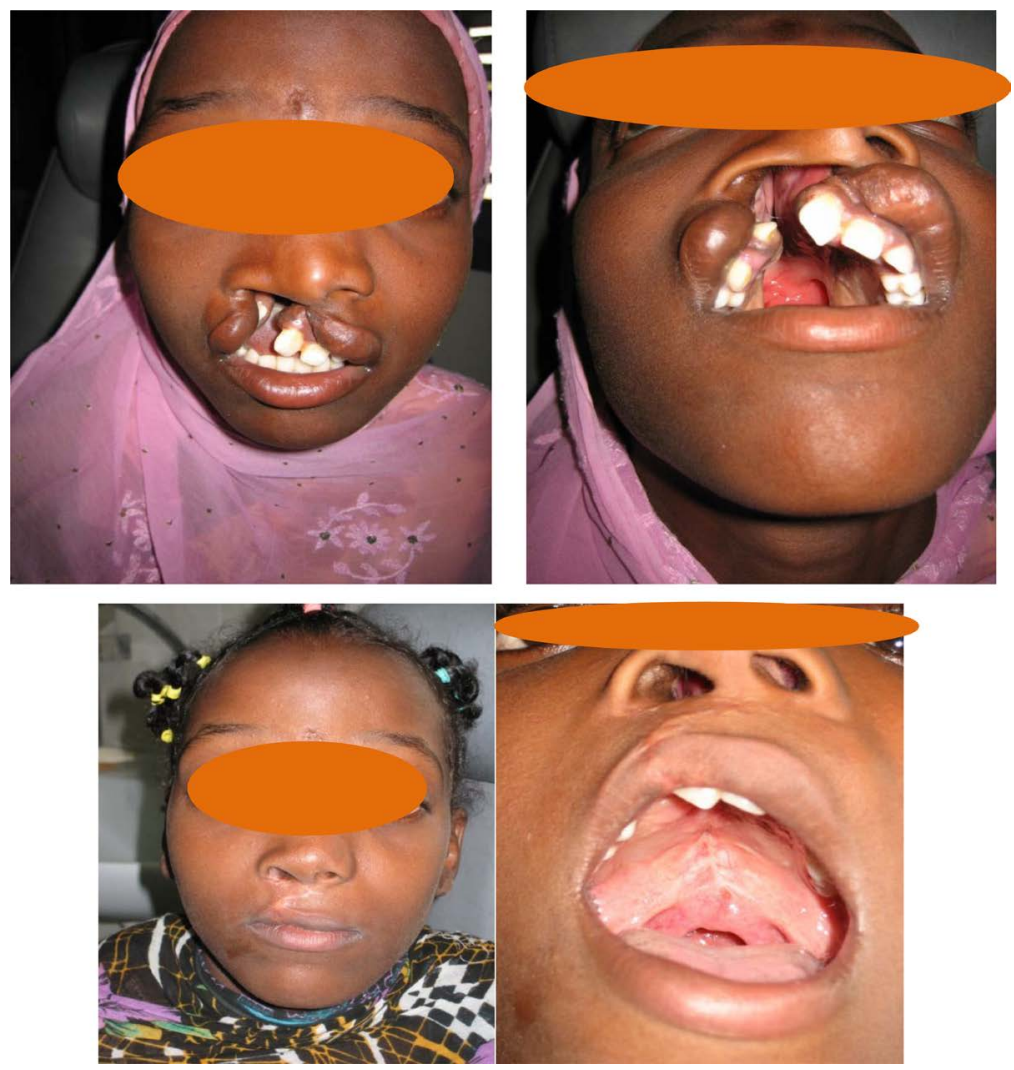

Figure 6. Before and after surgery.

and the veil. The surgical treatment consisted of the resumption of the lip plasty, the closing of the palate and the re-inclusion-recoil of the pro labium. Re-inclusion was made possible by abrading the alveolar bone laterally and placing a dental arch (Figure 7).

\section{Discussion}

In some western countries, nasolabial-palatal slits account for about 1.5 per 1000 births [2]. In Togo, they represent $1 / 500$ to $1 / 700$ births. The clefts of the primary palate would be twice as frequent in the boy as in the girl, while the clefts of the secondary palate would be much more frequent in the girl than the boy. The majority ( $95 \%$ ) of individuals with this recurrent deletion have inherited the deletion from a parent (who may or may not have clinical features related to the recurrent deletion). If a parent is heterozygous for the $16 \mathrm{p} 12.2$ recurrent deletion, the risk that the sibs of a proband would inherit the deletion is 50\%; however, the risk that sibs would be affected is less than $50 \%$ because of reduced penetrance for the deletion [7]. According to Kruse et al. [8], children of smoking mothers more often had right-sided clefts than children of nonsmoking mothers (42\% right-sided clefts in children of smoking mothers vs $31 \%$ of nonsmoking mothers). Children of smoking mothers more often had bilateral clefts than children of nonsmoking mothers (35\% bilateral clefts in children of smoking mothers vs $29 \%$ of nonsmoking mothers). In $5 \%$ of cases, the slits are associated 

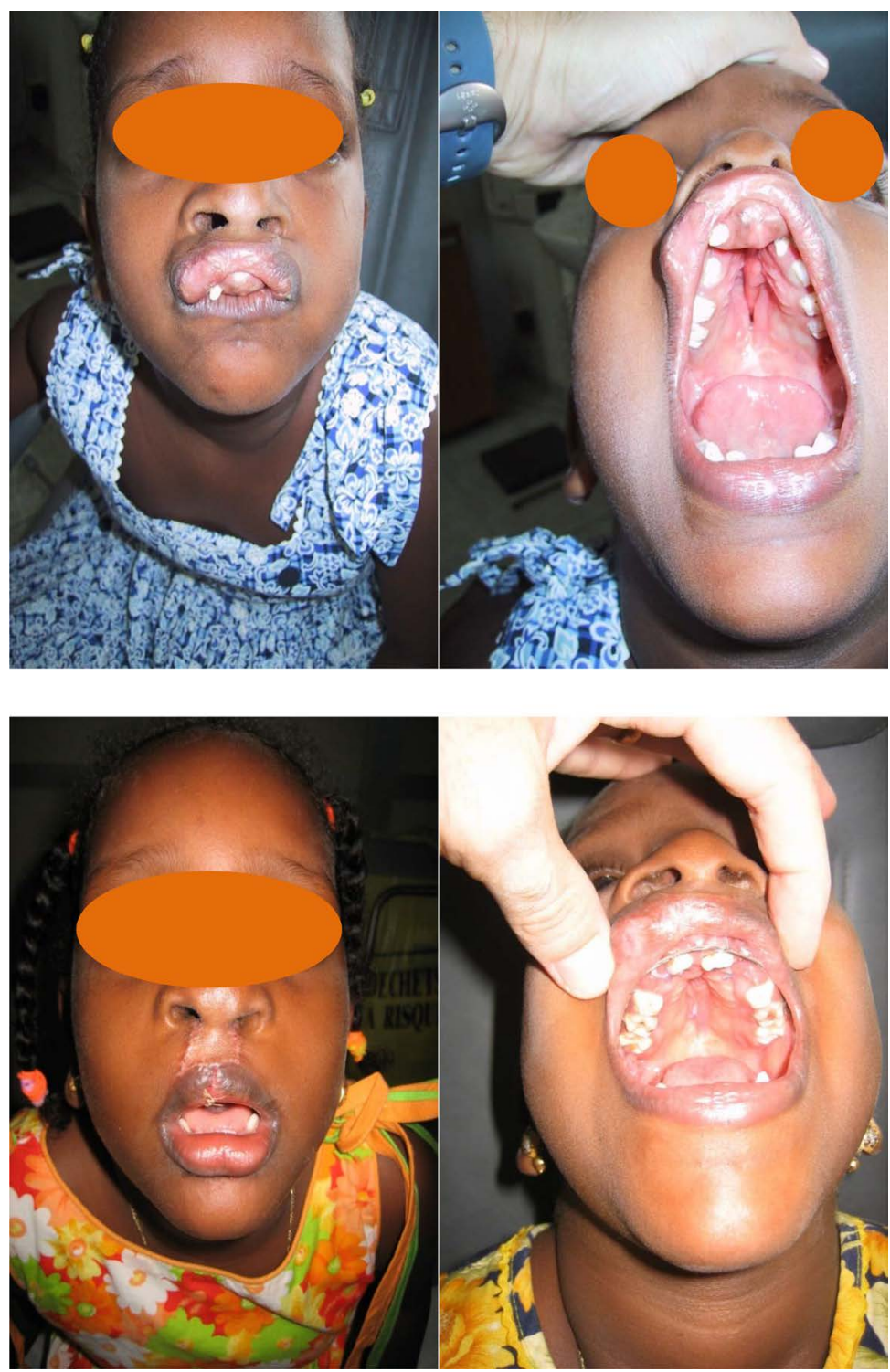

Figure 7. Before and after surgery.

with certain malformations, often benign (hexadactyly, club feet, hypospadias, congenital dislocation of the hip, CIA, CIV) or fall within the framework of malformation syndromes such as Pierre Robin's syndrome (cleft palatine, microretricandibulia, glossoptosis, respiratory function disorders, swallowing disorders) [9] [10] [11]. The cleft diagnosis is usually done at birth, but more and more the primary palatal clefts are prenatally diagnosed. The facial clefts have long been perceived as serious malformations and heavy sequelae. Today, the multidisciplinary therapeutic management of clefts has greatly improved the future of children with these malformations in developed countries [12] [13]. These authors advocate the need for many practitioners to receive specialized training in these types of treatment, including orthodontists. The clefts of the primary palate and the secondary palate are the most frequent congenital malformations of the cephalic extremity. They are due to a lack of welding embryo- 
nic buds during the first weeks of embryogenesis. There are 3 types of clefts: primary palatal clefts (uni or bilateral), secondary palatal clefts (uni or bilateral), and primary and secondary palate clefts (uni or bilateral). Their complex treatment extends from the birth to the end of the growth: surgery of the initial closure of the cleft, then secondary correction of the abnormalities induced notably by the growth, and a complementary multidisciplinary otological, orthophonic, orthodontic treatment [13] [14]. No consensus has yet been reached on the ideal schedule to propose for the management of labial-alveolar-palatal clefts. Some Western authors advocate early reconstruction in the first weeks of life. Some teams adopted and updated the protocol of Psaume and Maleck: isolated cleft lip and alveolar: repair at 2 months; total unilateral cleft lip and palate: 3 -month veloplasty, repair of the lip, nose and bony palate at 5 months, pharyngoplasty at 6 years; Bilateral total cleft lip and palate: flexible neonatal closure at 3 months, veloplasty at 3 months; 1 st side $=>$ lip, bony palate, nose at 5 months; 2 nd side $=>$ lip at 7 months; isolated velopalatine cleft: 2 beats; veil at 3 months, bony palate at 5 months. In addition to surgical treatment, the dentofacial and orthodontic orthopedic component is necessary to ensure a satisfactory result in the harmonious development of the face. Thus dentofacial orthopedic treatment can start in mixed dentition. The Quad Helix allows at best a maxillary expansion for the correction of the endomaxillie; in the sagittal direction, extraoral traction (Delaire mask) or class III mechanics can compensate for growth defects to reduce skeletal classes III. The objectives of orthodontic treatment in mixed dentition are to contain the disjointed bone fragments, correct the incisor malpositions and always keep space for the lateral, to put in normal occlusion the premolars and the canines, to restore a curve of normal arcade to the maxilla, and correct the inversions of the articulated. After these requirements, a palatal restraint plate maintains the result until the completion of gingivoperiostoplasty or bone grafting. According to the different classes of Angle, suitable orthodontic-surgical treatment will be agreed. It should be remembered that the exact modalities and the chronology depend on the habits of the teams, but the whole of the care must remain coherent and enable simple solutions to prevent the risk of complications. Why are Western surgeons coming on humanitarian missions to operate lunges in underdeveloped countries? When considering the question as to why Western surgeons are coming on humanitarian missions to operate in underdeveloped countries, there may be two reasons. First, there is a human aspect: Western practitioners and their entourage will receive a sense of joy and accomplishment by helping others, together with a sense of achievement, having been selected by leaders of their non-governmental organization enabling them to practice surgery in a different environment from that of the metropolis. Second, on a technical level, Western practitioners have an opportunity to share knowledge and teaching methods between the novice professional and the experienced professional [15] [16] [17]. The remoteness of the populations from the medical reference structures and an insufficient technical platform explained in 
part the advanced age of certain patients in our study. There are many important differences between a "humanitarian" activity and health care in a specialized referral medical facility. In hospital infrastructure, these pathologies are supported in hyperspecialized services of Maxillofacial Surgery or Pediatric Plastic Surgery with a precise operating schedule, and often prenatal screening [18] [19] [20]. In the same way the technologies used are modern and expensive (orthodontic treatment, with bone grafts, and secondary placement of dental implants). The care of the patient is global, multidisciplinary for the different slots; labio-maxillary (Maxillofacial surgeons), nose correction (Plasticians), management of sero-mucosal otitis (ENT), and dental follow-up by Stomatologists and Dentists, etc. In developing countries, the operational schedule is often uncertain, due to the lack of availability of specialized medical teams, the remoteness of rural populations and the financial constraints that this imposes on families. The different times are grouped, accelerated or not realized. For families, the aesthetic aspect often takes precedence over the functional aspect. Medical care is a real humanitarian problem, and Western demands need to be re-evaluated and reflected according to the child's priorities and the environment. What have been the challenges to take up this pathology in developing countries? Most often patients are hosted by a host family, and the length of stay is necessarily limited. Evacuation possibilities to a more affluent country are extremely limited. Without any insurance, social security, mutual insurance or state aid, sophisticated health care remains beyond the reach of middle-class populations. A significant obstacle in the management is the absence or the insufficiency of possibilities of speech therapy to speak, or to feed oneself. Orthodontics is also very limited because of the cost of services and the lack of practitioners. The management of this pathology in precarious situations must be pragmatic [21], controlled by the efficiency and the reliability of the realized gestures (because in case of failure of the intervention, it is almost impossible for the patients to be able to profit from a second displacement for a re-intervention). The intervention should therefore reduce to the strict minimum, the total number of operations per individual. The surgical calendar is very different from what is done in developed countries for the reasons already mentioned. It should be noted that there is no consensus on this subject and that different calendars are proposed according to the authors [4]: 1) a reconstruction very early, from the first week; 2) a general treatment of the veil at 3 months, and secondarily at 6 months the repair of the lip and the palate; 3 ) recommends taking care of the lip and the veil at 3 months, then repairing the palate at 9 months; 4) many practitioners take care of the lip and the veil at 6 months and the palate 1 year later and 5) do the surgery of the palate only around 3 months to 12 years.

\section{Conclusion}

The labial-alveolar-palatal clefts represent a group of pathologies which require a highly specialized management for both the surgical treatment as well as for the 
support of the patient and his/her family. The treatment of this type of pathology should not be reserved for developed countries. Care in a precarious environment is possible, with equally satisfactory results, allowing these children for the most part to find their place in society. Our experience in this work shows that in a precarious environment, even without specialized training, with access to a database and useful information, good results are possible, as well as a satisfactory management of some pathologies which would appear inaccessible in this context.

\section{Conflicts of Interest}

The authors declare no conflicts of interest regarding the publication of this paper.

\section{References}

[1] Cooper, M.E., Ratay, J.S. and Marazita, M.L. (2006) Asian Oral-Facial Cleft Birth Prevalence. The Cleft Palate-Craniofacial Journal, 43, 580-589. https://doi.org/10.1597/05-167

[2] Barrabé, A., Louvrier, A., Allary, R., Moussa, M., Boutros, M. and Bénateau, H. (2020) Infantile and Adult Mortality in Precarious Conditions. Journal of Stomatology, Oral and Maxillofacial Surgery, 121, 49-52. https://doi.org/10.1016/j.jormas.2019.04.010

[3] Olasoji, H.O., Hassan, A. and Ligali, T.O. (2009) Challenges of Cleft Care in Africa. African Journal of Medicine and Medical Sciences, 38, 303-310.

[4] Chaudré, F. and Garabédian, E.N. (2003) Chirurgie des fentes labio-vélo-palatines. Encyclopédie Médico-Chirurgicale, Technique chirurgicale-Tête et cou, 46-220.

[5] Volk, A.S., Davis, M.J., Dempsey, R.F., Masoumy, M., Desai, P.K., Hubli, E. and Buchanan, E.P. (2020) A Global Evaluation of Surgical Techniques and Results of Unilateral Cleft Lip Repairs. Journal of Craniofacial Surgery, 31, 2276-2279. https://doi.org/10.1097/SCS.0000000000006813

[6] Chapchay, K., Zaga, J., Billig, A., Adler, N. and Margulis, A. (2019) Surgical Technique for Nasal Cleft Repair. Annals of Plastic Surgery, 82, 289-291. https://doi.org/10.1097/SAP.0000000000001688

[7] Girirajan, S., Pizzo, L., Moeschler, J. and Rosenfeld, J. (2015) 16p12.2 Recurrent Deletion. In: Adam, M.P., Ardinger, H.H., Pagon, R.A., Wallace, S.E., Bean, L.J.H., Mirzaa, G. and Amemiya, A., Eds., GeneReviews ${ }^{\circledast}$. University of Washington, Seattle, 1993-2021.

[8] Kruse, T., Mangold, E. and Braumann, B. (2021) Impact of Maternal Smoking on Nonsyndromic Clefts: Sex-Specific Associations with Side and Laterality. The Cleft Palate-Craniofacial Journal, 58, 181-188. https://doi.org/10.1177/1055665620951099

[9] Drew, S.J. (2014) Clefting Syndromes. Atlas of the Oral and Maxillofacial Surgery Clinics of North America, 22, 175-181. https://doi.org/10.1016/j.cxom.2014.05.001

[10] Li, J., Rodriguez, G., Han, X., Janečková, E., Kahng, S., Song, B. and Chai, Y. (2019) Regulatory Mechanisms of Soft Palate Development and Malformations. Journal of Dental Research, 98, 959-967. https://doi.org/10.1177/0022034519851786

[11] Smarius, B., Loozen, C., Manten, W., Bekker, M., Pistorius, L. and Breugem, C. (2017) Accurate Diagnosis of Prenatal Cleft Lip/Palate by Understanding the Embryology. World Journal of Methodology, 7, 93-100. 
https://doi.org/10.5662/wjm.v7.i3.93

[12] Crockett, D.J. and Goudy, S.L (2014) Cleft Lip and Palate. Facial Plastic Surgery Clinics of North America, 22, 573-586. https://doi.org/10.1016/j.fsc.2014.07.002

[13] Vargas, C.R., Long, T.C. and Kumar, A.R. (2020) Trainee Operative Autonomy in Plastic Surgery. Annals of Plastic Surgery, 85, 553-560. https://doi.org/10.1097/SAP.0000000000002210

[14] Timashpolsky, A., Schild, S.D., Ballard, D.P., Leventer, S.P., Rosenfeld, R.M. and Plum, A.W. (2021) Management of Type 1 Laryngeal Clefts: A Systematic Review and Meta-Analysis. Otolaryngology_Head and Neck Surgery, 164, 489-500. https://doi.org/10.1177/0194599820947742

[15] Bowe, S.N. and Hartnick, C.J. (2017) Management of Type I and Type II Laryngeal Clefts: Controversies and Evidence. Current Opinion in Otolaryngology \& Head and Neck Surgery, 25, 506-513. https://doi.org/10.1097/MOO.0000000000000414

[16] Butali, A., Adeyemo, W.L., Mossey, P.A., Olasoji, H.O., Onah, I.I., Adebola, A., Akintububo, A., James, O., Adeosun, O.O., Ogunlewe, M.O., Ladeinde, A.L., Mofikoya, B.O., Adeyemi, M.O., Ekhaguere, O.A., Emeka, C. and Awoyale, T.A. (2014) The Nigeriacran Collaboration. Prevalence of Orofacial Clefts in Nigeria. The Cleft Palate-Craniofacial Journal, 51, 320-325.

https://doi.org/10.1597/12-135

[17] Aziz, S.R., Ziccardi, V.B. and Chuang, S.K. (2012) Survey of Residents Who Have Participated in Humanitarian Medical Missions. Journal of Oral and Maxillofacial Surgery, 70, e147-e157. https://doi.org/10.1016/j.joms.2011.10.007

[18] Morris, L.M. and Tatum, S.A. (2016) Craniofacial Surgery for the Facial Plastic Surgeon. Facial Plastic Surgery Clinics of North America, 24, xiii. https://doi.org/10.1016/j.fsc.2016.08.001

[19] Tollefson, T.T. (2017) What Is Global Surgery? Current Opinion in Otolaryngology \& Head and Neck Surgery, 25, 255-257. https://doi.org/10.1097/MOO.0000000000000381

[20] Greenidge, E., Krieves, M. and Solorzano, R. (2020) Global Anesthesia in Oral and Maxillofacial Surgery. Oral and Maxillofacial Surgery Clinics of North America, 32, 427-436. https://doi.org/10.1016/j.coms.2020.04.004

[21] Lee, J.S., Roser, S.M. and Aziz, S.R. (2020) Oral and Maxillofacial Surgery in Low-Income and Middle-Income Countries. Oral and Maxillofacial Surgery Clinics of North America, 32, 355-365. https://doi.org/10.1016/j.coms.2020.04.001 